\title{
The relevance of herders' local ecological knowledge on coping with livestock losses during harsh winters in western Mongolia
}

\author{
Takuya Soma ${ }^{1,2}$ and Eva Schlecht ${ }^{*}$ (D)
}

\begin{abstract}
In many regions of the world, traditional and local ecological knowledge is still important today for coping with environmental challenges. This study explored the relevance of such knowledge for predicting and coping with harsh winter conditions (dzud) in a remote area of western Mongolia, where government support to disasteraffected herders is restricted by weak infrastructure. Structured face-to-face interviews were held in 50 households $(\mathrm{HHs})$, addressing aspects of livestock possession and management as well as disaster prediction and mitigation. The responses disclosed that livestock losses during the 2009/10 dzud averaged 112.4 animals per $\mathrm{HH}$, equaling nearly $80 \%$ of the interviewees' total livestock possession in summer 2013. To reduce such high losses in the future, herders planned to improve their hay-making efforts and winter pen preparation. However, they also stated that the earliest signs for a dzud occur in September, when it is already too late for substantial hay-making. Therefore, some herders underlined the necessity of maintaining livestock productivity through segregated summer grazing of specific animal groups, controlled mating and early sale of weak livestock. Animals are then entering a harsh winter in good body condition. National and international organizations wishing to support livestock keepers in this and similar regions should therefore highlight the relevance of local strategies for disaster prevention and support community-based approaches that can compensate for the prevalent lack of family labour.
\end{abstract}

Keywords: Altai Mountains, Climatic hazards, Disaster reduction, Local ecological knowledge, Transhumant animal husbandry, Resilience

\section{Introduction}

Traditional ecological knowledge (TEK) and local ecological knowledge (LEK) is knowledge held by indigenous and local cultures that often reflects the long-term past (TEK) and present (LEK) experience gained from the intimate involvement of humans with their local ecosystem (Berkes 1999; Chapman 2007; Martin et al. 2010). As an integrated knowledge system of verbal information, recognition and belief, TEK is transmitted from one generation to the next and is amended through new observation and experiences (that is, LEK; Fernandez-Gimenez 2000; Schafer and Reis 2008). TEK has been especially described by anthropologists from

\footnotetext{
* Correspondence: tropanimals@uni-kassel.de

${ }^{1}$ Section Animal Husbandry in the Tropics and Subtropics, University of Kassel and Georg-August-Universität Göttingen, Steinstrasse 19, 37213 Witzenhausen, Germany

Full list of author information is available at the end of the article
}

the viewpoint of culture and ethnological distinction (Berkes 1999). Sonak (2014) argued that successful and sustainable livelihood strategies of local cultures have often preserved their natural environments' health over centuries.

During the past two decades when the global society increasingly realized the need for long-term sustainability of agro-ecosystems management, improved resource use efficiency and better reconciliation of societal needs with natural ecosystems' health (e.g. WCED 1987; Mebratu 1998; Fernandez-Gimenez et al. 2016), scientists and ecological practitioners started to revaluate TEK held by communities that are strongly engaged in traditional subsistence systems (Menzies 2006; Martin et al. 2010). Scientists have tried to better integrate TEK with modern approaches of natural resources management and conservation strategies in different domains of human-environment interactions, such as inland and marine fisheries in Brazil (Schafer and Reis 2008; Teixeira et al. 2013), forestry and traditional 
rice-farming in Japan (Indrawan et al. 2014), as well as small mammals' conservation in the Dominican Republic (Turvey et al. 2014), and positive effects of the approach were reported.

Today, TEK and its substantial contribution to nature guardianship is vanishing among Mongolian herders (Fernandez-Gimenez et al. 2016). The loss of TEK and LEK on animal husbandry is viewed as one of the negative consequences of totalitarian collective farming during the 70-year socialist period in Mongolia and the subsequent social turbulences during the democratization process in the 1990s (FernandezGimenez 2000). There is recent evidence of spatially concentrated exploitation of grazing resources leading to rangeland degradation (Altmann et al. 2016; Jordan et al. 2016) and eventually severe livestock losses in the case of extreme environmental conditions such as an extremely harsh winter (Soma 2014).

For the four-year period of 1999 to 2002, the occurrence of three subsequent disastrous winters (called $d z u d$ in the Mongolian language) and high livestock mortality was associated with a low remotely sensed normalized difference vegetation index (NDVI) in summer, high snow-water equivalent in winter and high livestock mortality or a high livestock population in the previous year (Saizen et al. 2010). For the same period, Begzsuren et al. (2004) reported an average annual livestock mortality of $18 \%$ in years when both summer drought and severe winter weather struck in Gobi Gurvansaikhan National Park. This mortality value was $4.8 \%$ higher than the mortality in years with only $d z u d$ and $7 \%$ higher than the mortality in years with only summer drought, indicating that livestock survival is more sensitive to $d z u d$ than to summer drought (Begzsuren et al. 2004). Therefore, it is not surprising that the disastrous $d z u d$ (winter) of 2009/10 triggered a series of studies that tried to establish cause-effect relationships for the vast livestock losses, and pointed to strategies that might help reduce the impact of disaster in the future (Sternberg 2010; Fernandez-Gimenez et al. 2012; Addison and Brown 2014; Middleton et al. 2015). As underlined by Fernandez-Gimenez et al. (2012), $d z u d$ is no singular environmental event but rather a complex social-ecological phenomenon, and vulnerability to $d z u d$ is a function of interacting physical, biological, socio-economic and institutional factors. Since governmental support of herders was drastically reduced after the end of socialism in Mongolia, Addison and Brown (2014) evaluated the financial return to a set of locally used herd management strategies under the scenarios of a mild, normal and strong winter. However, their propositions rely on well-functioning markets for the purchase of livestock feeds and the sale of live animals and livestock products by the herders, which do not often exist in remote areas with weak infrastructure in Mongolia. With this case study, we therefore wanted to explore whether, and to which extent, traditional and local ecological knowledge are of relevance for predicting and coping with harsh winter conditions in an area where physical and economic infrastructure is particularly weak.

\section{Study area}

The study area is located across the border of Bayan-Ölgii province (aimag) and Khovd province in the Altai Mountains (Figure 1), the most poorly developed rural area in Mongolia, $2000 \mathrm{~km}$ west of the country's capital Ulaanbaatar (Soma 2014). In this region, pastureland is shared by three ethnic minorities: the Kazakh, the Torguud, and the Uriankhai (Soma 2014; Mroz 2015). There are significant differences between these ethnic groups, both at a macroscale (religion, philosophy, language, history of regional settlement) and at a micro-scale (livelihood, way of animal herding, style of house and costume; Saruul 2011). The three ethnic groups practice a collective lifestyle which is based on tight kinship relations among households (HHs) who set up their homesteads (portable round tents called ger in the Mongolian language) close to each other in socalled khot ail. These are groupings of livestock-keeping families, nowadays typically comprising 2 to 12 households, who jointly practice a transhumant way of living and herding (Bold 1996; Fernandez-Gimenez et al. 2015).

In the framework of a larger research project that focused on the effects of climatic changes and land use intensification in the transborder Altai-Dzungarian region of Mongolia and China (Jordan et al. 2016, 2018), four summer pasture settlements were purposefully selected for the present study. These were:

\begin{tabular}{|c|c|c|}
\hline 1. Altztai Holoo (AH) & 2590 to $2662 \mathrm{~m}$ a.s.l. & $\left(46^{\circ} 39^{\prime} 26^{\prime \prime} \mathrm{N} / 91^{\circ} 50^{\prime} 39^{\prime \prime} \mathrm{E}\right)$ \\
\hline 2. Tsunhal Nur (TN) & 2417 m a.s.l. & $\left(46^{\circ} 39^{\prime} 59^{\prime \prime} \mathrm{N} / 91^{\circ} 39^{\prime} 20^{\prime \prime} \mathrm{E}\right)$ \\
\hline 3. Hoshoot (HS) & 2737 m a.s.l. & $\left(46^{\circ} 38^{\prime} 50^{\prime \prime} \mathrm{N} / 91^{\circ} 28^{\prime} 57^{\prime \prime} \mathrm{E}\right)$ \\
\hline 4. Dont-Temult (DT) & $2468 \mathrm{~m}$ a.s.l. & $\left(46^{\circ} 40^{\prime} 56^{\prime \prime} \mathrm{N} / 91^{\circ} 14^{\prime} 18^{\prime \prime} \mathrm{E}\right)$ \\
\hline
\end{tabular}

At the time of study, Torguud (11 HHs) settled in $\mathrm{AH}$, Uriankhai in HS and DT (5 and 14 HHs, respectively) and all three groups (38 HHs altogether) were found in TN. Across ethnic groups, the average household size $($ mean $\pm \mathrm{SD}$ ) was $5.1 \pm 1.7$, where $3.2 \pm 1.4$ were $>18$ years old (Tsevegmed 2016).

\section{Methods}

Data collection

The study was conducted from 24 June to 20 August 2013. All households in each settlement were initially approached and asked whether they would be willing to 

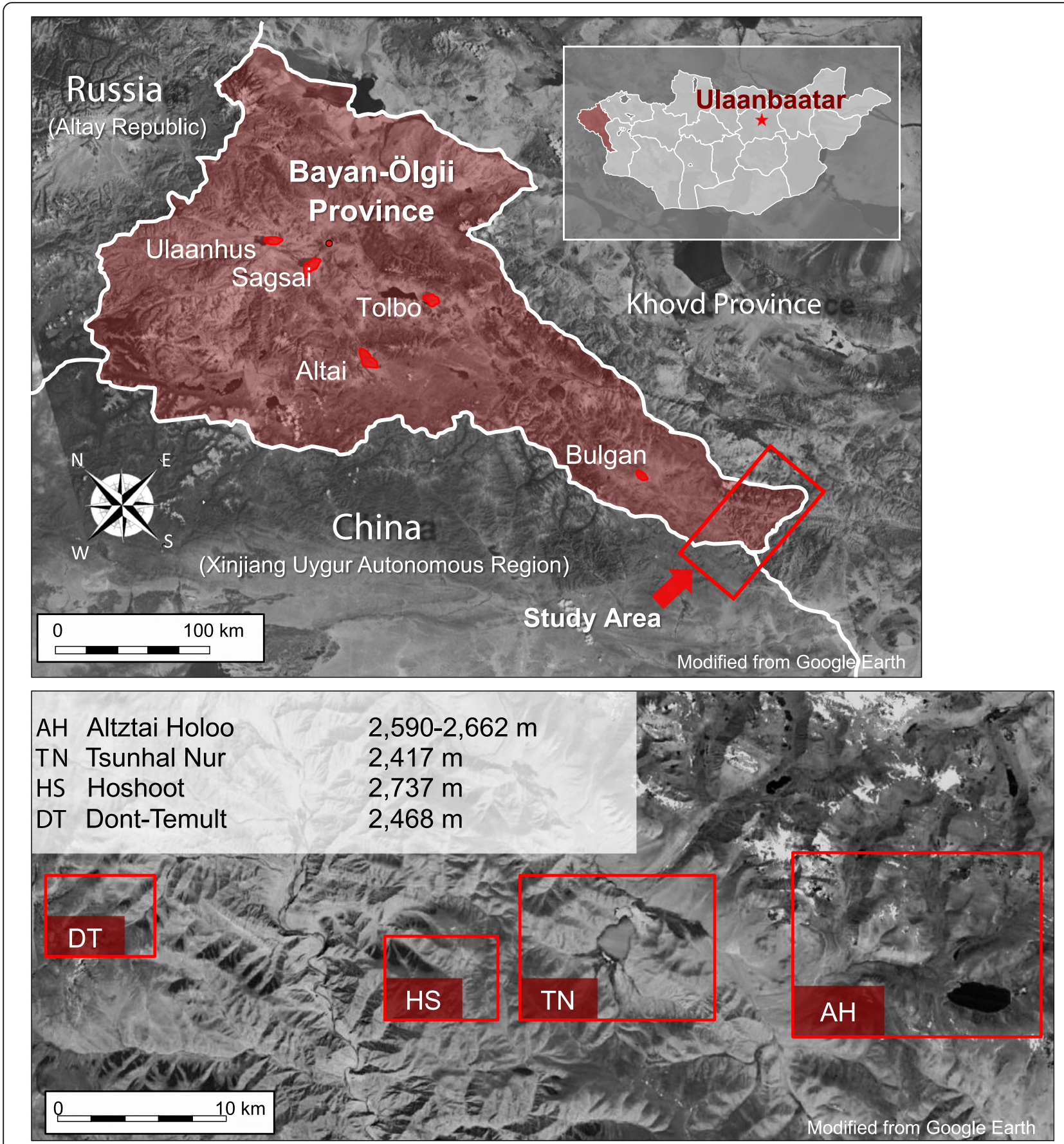

Figure 1 Location of the study region (above) within Mongolia (small inset) and of the four study sites in the Mongolian Altai (below). Sites DT, HS and TN are located in Bayan-Ölgii province; site AH is located in Khovd province. Image ๑ 2014 Digital Globe; Landsat image, modified after download from Google Earth

participate in an interview on livestock numbers, management practices and disaster-related ecological knowledge and strategies. Households responding positively (8 in AH, 24 in TN, 4 in HS, 14 in DT) were then visited again to carry out the interview. As the sampling approach was based on a household's voluntary participation, the distribution of households across settlements and ethnic groups was not proportional to settlement and group size, respectively. Data were collected through structured face-to-face interviews with a pretested questionnaire. The interviews were held inside the household's ger and specifically addressed a senior family member. The interviews were held in the Mongolian language, whereby a Mongolian assistant asked 21 
predefined questions (12 closed multiple-choice questions that mostly allowed multiple answers and 9 comment-type questions). Subsequently, the first author and the assistant engaged in an open conversation with the interviewee, which was recorded in writing. In total, one household visit lasted between 60 and $90 \mathrm{~min}$.

\section{Data analysis}

Out of the 50 interviewed persons (23 female, 27 male), 2 did not provide univocal responses to some of the questions; these answers were treated as missing values in the data analysis. Qualitative information collected in the open conversation and recorded in the English language was subjected to conventional and summative content analysis. Quantitative data from the structured part of the interview was entered in Microsoft Excel ${ }^{\circ}$ spreadsheets, whereby text variables were coded into binary or nominal/ordinal dummy variables as appropriate. Wherever applicable, data was statistically analysed in SPSS for Windows, Version 20 (IBM Corporation, 2011). In a first step, the residuals of continuous variables were checked for normal distribution using the Kolmogorov-Smirnov test. As distribution of all variables was non-normal, differences between ethnic groups and summer camp locations were explored using nonparametric tests. Chi-square (Fisher's exact) test was thereby used for categorical variables and Kruskal-Wallis test for continuous variables. Linear relationships were analysed applying Pearson correlation statistics. Significance was declared at $p \leq 0.05$.

\section{Results}

\section{Livestock ownership and extent of $d z u d$ losses}

All of the surveyed households stated that they and their herds had been affected by the 2009/10 dzud. Based on the number of adult animals among a household's total livestock possession (TLP) in August 2013, we distinguished three different types of herd owners, namely large herders (Lhs) with $\geq 201$ head, medium herders (Mhs) with 101 to 200 head and small herders (Shs) with $\leq 100$ head of adult animals (Table 1). Although we acknowledge the contextdependent nature of the concept (Murphy 2014), we further refer to these three types as wealth strata. Together, the $10 \mathrm{HHs}$ forming the Lh stratum possessed $55.5 \%$ of the 50 HHs' total livestock in August 2013, whereas the 27 HHs $(60 \%)$ of the Sh stratum possessed $22.7 \%$ of the total livestock. Yak and khainag (hybrid of yak and cattle) were only kept by Uriankhai families. Across the three wealth strata, the number of adult yak was negatively correlated to that of adult sheep $(r=-0.98)$ and camels $(r=-0.92)$; the latter were mainly owned by herders from the Lh stratum, especially Torguud.

The total number of livestock lost across the $50 \mathrm{HHs}$ during the period 2005 to 2011 was 7040 head but varied from 1 to 415 head for individual households (mean \pm S.E. $149 \pm 16.5$, median 123). The losses caused by the $d z u d$ in $2009 / 10$ were higher (Table 2), totalling 5619 head for the $50 \mathrm{HHs}$ and ranging from 1 to 385 head per HH (112 \pm 14.5 , median: 95). This was almost equal to $80 \%$ of the $50 \mathrm{HHs}$ 'total livestock possession in August 2013 and 1.8 times more than the total number of 3101 newborn animals counted in August 2013. Expressed in percent of the total livestock possession in 2013, the wealthier livestock keepers experienced less annual livestock losses for the period winter 2005/06 to 2010/11 and less losses in the 2009/10 dzud than the poorer livestock keepers. Median livestock losses of Kazakh HHs were 161 heads in the 2009/10 dzud, which was two times higher than the (median) losses of Uriankhai (95 head) and of Torguud (84 head). Especially the latter ethnic group, who in summer 2013 kept half (51.3\%) of all livestock among the $50 \mathrm{HHs}$, seemed to have suffered least during the 2009/10 dzud. Despite these indications for a wealth and ethnicity component in the vulnerability to $d z u d$, differences in livestock losses between the three ethnic groups and between the three wealth strata (Table 3$)$ were not significant $(p>0.05)$.

As far as the 2009/10 livestock losses are concerned, significant differences $(p \leq 0.05)$ were observed between animal species (Table 4). Local herders stated that yak and goats easily freeze to death in a $d z u d$, and the higher mortality rate calculated for these species supports this perception. Yak mortality accounted for $2.4 \%$ of all livestock losses in 2009/10, although yak constituted only $0.7 \%$ of the $50 \mathrm{HHs}$ ' TLP. The number of lost goats increased linearly with a household's possession of adult goats $(r=0.899)$. The total loss of 3782 goats in 2009/10 was higher than the total number of sheep and goats possessed by the $50 \mathrm{HHs}$ in August 2013 and accounted for $67.3 \%$ of livestock losses across the $50 \mathrm{HHs}$ in this $d z u d$.

\section{Ecological knowledge transmission and local dzud-coping strategies}

The inter-generational transmission of traditional and local ecological knowledge for the prevention of $d z u d$ damage was low, since $88 \%$ of the interviewees claimed that they had not acquired such knowledge about grazing, livestock management or specific protective actions against $d z u d$ from their parents or neighbours. However, the experiences in the wake of the 2009/10 dzud had increased herders' appreciation of local ecological knowledge across ethnic groups and wealth strata. Some herders $(n=18)$ stated that they became aware of the importance of local ecological knowledge and related strategies after the last $d z u d$, others $(n=14)$ confirmed that they rediscovered the significance of hay-making and hay-stocking and a third group $(n=11)$ had 
Table 1 Livestock possession of households (HHs) in the Mongolian Altai owning large herds (Lhs), medium-size herds (Mhs) and small herds (Shs) in summer 2013

\begin{tabular}{|c|c|c|c|c|c|c|c|c|}
\hline \multirow{2}{*}{$\begin{array}{l}\text { Wealth } \\
\text { stratum }\end{array}$} & \multirow[t]{2}{*}{ Variable } & \multicolumn{7}{|c|}{ Livestock species } \\
\hline & & Sheep & Goat & Cattle & Yak & Horse & Camel & Total \\
\hline \multirow{7}{*}{$\begin{array}{l}\text { Lh } \\
(n=10)\end{array}$} & Total head $(n)$ & 1165 & 2009 & 308 & 1 & 172 & 87 & 3742 \\
\hline & Thereof newborn $(n)$ & 660 & 890 & 141 & 0 & 0 & 0 & 1691 \\
\hline & Median per $\mathrm{HH}(n)$ & 111 & 202 & 22 & 0 & 13 & 6 & 370 \\
\hline & Mean per $\mathrm{HH}(n)$ & 117 & 201 & 31 & 0 & 17 & 9 & 374 \\
\hline & SD & 76.6 & 74.1 & 27.5 & 0.3 & 12.8 & 6.1 & 120.6 \\
\hline & Proportion in herd (\%) & 31.1 & 53.7 & 8.2 & 0.0 & 4.6 & 2.3 & \\
\hline & Sheep/goat ratio & 0.37 & 0.63 & & & & & \\
\hline \multirow{7}{*}{$\begin{array}{l}\text { Mh } \\
(n=10)\end{array}$} & Total head $(n)$ & 376 & 820 & 109 & 17 & 75 & 77 & 1474 \\
\hline & Thereof newborn $(n)$ & 233 & 401 & 61 & 0 & 0 & 15 & 710 \\
\hline & Median per HH (n) & 35 & 79 & 12 & 0 & 7 & 3 & 145 \\
\hline & Mean per $\mathrm{HH}(n)$ & 38 & 82 & 11 & 2 & 8 & 8 & 147 \\
\hline & SD & 25.4 & 22.8 & 4.5 & 2.7 & 2.0 & 13.2 & 34.1 \\
\hline & Proportion in herd (\%) & 25.5 & 55.6 & 7.4 & 1.2 & 5.1 & 5.2 & \\
\hline & Sheep/goat ratio & 0.31 & 0.69 & & & & & \\
\hline \multirow{7}{*}{$\begin{array}{l}\text { Sh } \\
(n=30)\end{array}$} & Total head (n) & 90 & 1096 & 189 & 29 & 85 & 43 & 1532 \\
\hline & Thereof newborn $(n)$ & 50 & 511 & 92 & 0 & 0 & 0 & 653 \\
\hline & Median per $\mathrm{HH}(n)$ & 3 & 40 & 7 & 0 & 3 & 0 & 59 \\
\hline & Mean per HH (n) & 3 & 41 & 7 & 1 & 3 & 2 & 57 \\
\hline & SD & 3.6 & 21.3 & 6.1 & 1.9 & 2.2 & 4.8 & 23.8 \\
\hline & Proportion in herd (\%) & 5.9 & 71.5 & 12.3 & 1.9 & 5.5 & 2.8 & \\
\hline & Sheep/goat ratio & 0.08 & 0.92 & & & & & \\
\hline \multirow{7}{*}{$\begin{array}{l}\text { Total } \\
(n=50)\end{array}$} & Total head $(n)$ & 1631 & 3925 & 606 & 47 & 332 & 207 & 6748 \\
\hline & Thereof newborn $(n)$ & 943 & 1802 & 294 & 0 & 0 & 15 & 3054 \\
\hline & Median per HH (n) & 7 & 62 & 9 & 0 & 5 & 1 & 87 \\
\hline & Mean per $\mathrm{HH}(n)$ & 35 & 84 & 13 & 1 & 7 & 4 & 144 \\
\hline & SD & 58.2 & 74.4 & 16.6 & 2.0 & 8.3 & 8.3 & 139.0 \\
\hline & Proportion in herd (\%) & 24.2 & 58.2 & 9.0 & 0.7 & 4.9 & 3.1 & \\
\hline & Sheep/goat ratio & 0.29 & 0.71 & & & & & \\
\hline
\end{tabular}

Chi-square test: except for yak, $p \leq 0.01$ for ethnic group and wealth stratum

acquired basic skills of livestock management. Conversely, 26 respondents claimed not to engage in particular preventive actions against $d z u d$, whereby there were no differences between male and female respondents (M 12, F 14) or between ethnic groups. Nevertheless, most herders $(n=40)$ stressed the importance of hay-making and hay-stocking to prepare for a $d z u d$. Improving the animals' winter pen, the wind-protection fences and reinforcing the manure layer on the pen floor were also mentioned as being important $d z u d$ preparation measures $(n=24)$. The respondents explained that about $1 \mathrm{~m}$ of dry animal manure needs to be piled up on the pen floor to protect the animals from the frozen terrain underneath. In addition, the pen floor needs to be cleaned every day and frozen urine patches have to be removed to keep the inside air warm. The fence around the pen and adjacent yard must be fixed and gaps filled with manure, wood or stones to keep off cold wind. These measures require dry manure from cattle and yak, stones and wood. Manure is difficult to obtain for many Sh and some Mh households, because of a limited number of cattle and lack of manpower for the related physical work. The acquisition of concentrate feed and nutritious forage was not viewed as a realistic coping strategy against $d z u d$ because of high costs. Nevertheless, all interviewees hoped to be supported in this way by the government in case of another harsh winter.

Six relatively wealthy herders who had lost between 18 and 522 head of livestock during 2005 to 2010 claimed to practice otor due to revitalized awareness of its 
Table 2 Annual livestock losses (head) from 2005 to 2011 as recalled by 50 interviewed herder households in the Bayan-Ölgii and Khovd provinces (Mongolian Altai)

\begin{tabular}{lllllllll}
\hline Livestock species & $2005 / 06^{\mathrm{a}}$ & $2006 / 07$ & $2007 / 08$ & $2008 / 09$ & $2009 / 10^{\mathrm{b}}$ & $2010 / 11$ & $\begin{array}{l}\text { Cumulated } \\
\text { losses }\end{array}$ & $\begin{array}{l}\text { Share (\%) in } \\
\text { cumulated losses }\end{array}$ \\
\hline Sheep & 119 & 51 & 184 & 21 & 1226 & 41 & 1642 & 23.3 \\
Goat & 126 & 38 & 596 & 25 & 3782 & 44 & 4611 & 65.5 \\
Cattle & 11 & 1 & 21 & 0 & 198 & 14 & 245 & 3.5 \\
Yak & 0 & 0 & 33 & 0 & 121 & 12 & 166 & 2.4 \\
Horse & 17 & 0 & 26 & 1 & 286 & 22 & 352 & 5.0 \\
Camel & 2 & 0 & 4 & 0 & 6 & 12 & 24 & 0.3 \\
Total & 275 & 90 & 864 & 47 & 5619 & 145 & 7040 & 100 \\
Share (\%) in total losses & 3.9 & 1.3 & 12.3 & 0.7 & 79.8 & 2.1 & 100 & \\
\hline
\end{tabular}

Kruskal-Wallis test: across species, no significant differences in losses $(p>0.05)$ between ethnic groups and wealth strata

${ }^{a}$ Annual considerations, always starting in winter, i.e. November

${ }^{\mathrm{b}}$ Most recent $d z u d$ year at the time of interview

importance. The word otor means taking livestock to areas with good grazing away from the usual (residential) place (Tsevel $1966^{1}$ ). In practical terms, otor stands for the segregated grazing of small ruminants (especially fattening animals) on specific high-quality pastureland during summer and of large ruminants during winter. Often these separated animals are assigned to a specific herder.

Table 3 Average livestock losses in the Mongolian Altai during the 2009/10 dzud across ethnic groups and wealth strata

\begin{tabular}{llll}
\hline Group/stratum & Variable & Small ruminants & Large animals $^{\mathrm{b}}$ \\
\hline $\begin{array}{l}\text { Kazakh } \\
(n=7)\end{array}$ & Median & 160.0 & 5.0 \\
& Mean & 162.9 & 6.4 \\
& SD & 105.8 & 5.2 \\
Torguud & Median & 100.0 & 12.0 \\
$(n=12)$ & Mean & 129.6 & 15.4 \\
& SD & 122.7 & 14.9 \\
Uriankhai & Median & 79.5 & 7.0 \\
$(n=24)$ & Mean & 90.3 & 9.3 \\
& SD & 87.3 & 9.0 \\
Lh & Median & 110.0 & 10.5 \\
$(n=10)$ & Mean & 125.0 & 19.6 \\
& SD & 117.0 & 18.2 \\
Mh & Median & 115.0 & 9.5 \\
$(n=10)$ & Mean & 127.0 & 16.7 \\
& SD & 120.7 & 22.8 \\
Sh & Median & 77.0 & 5.5 \\
$(n=30)$ & Mean & 82.9 & 8.3 \\
& SD & 77.3 & 8.6 \\
\hline
\end{tabular}

Households owning large herds (Lhs), medium-size herds (Mhs) and small herds (Shs)

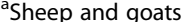

${ }^{\mathrm{b}}$ Cattle, yak, camels, horses

\section{Coping strategies employed and lessons learned in the 2009/10 dzud}

The most important strategy of many of the interviewed herders $(n=34)$ during the $2009 / 10$ dzud was 'to feed hay' to their livestock (Figure 2). 'Feeding concentrate' was only practiced by seven $\mathrm{HHs}$, of which five stated to have bought 'a lot' of concentrate feed at that time. Some herders complained about high prices and a lack of concentrate in the county centre. Four families fed their animals with the bark of aspen (Populus tremula L.) instead with hay. Aspen bark is a traditional rescue feed during severe winter feed shortage. Other measures that were recalled during the informal discussions were the following:

* I obtained hay/forage from the county/the administration ( $\mathrm{HSO1}$; $\mathrm{TNO3}^{2}$ ).

* I bought hay worth 2 million Mongolian Tugrik (ca. 1200 USD) (TN15).

* I gathered natural (rock) salts (TN17).

"I fed the leftovers of our meals (TN19).

* I gave horse faeces to cattle as a rescue feed (HS01).

" I scattered salt in the pen. It prevents freezing of livestock (DT01).

* I kept juveniles and small livestock inside our winter house (DT14).

* I practiced a traditional way of feeding as stated in a proverb: 'small ruminants need hay, large ruminants need grazing' (DT14).

* I slaughtered skinny livestock before the winter and preserved well-fed animals because they survive severe conditions (AH01, TN08).

Six herders stated that in 2009/10 they could do 'nothing against $d z u d$ ', and 20 stated that their actions were 'not sufficient', whereas the other interviewees considered their protective actions 'sufficient' $(n=23)$ or 'somehow okay' $(n=3)$. However, these herders had also lost 
Table 4 Cumulated livestock losses in the Mongolian Altai across ethnic groups and wealth strata during the 2009/10 dzud

\begin{tabular}{|c|c|c|c|c|c|c|c|c|}
\hline \multirow{2}{*}{$\begin{array}{l}\text { Ethnic } \\
\text { group }\end{array}$} & \multirow{2}{*}{$\begin{array}{l}\text { Wealth } \\
\text { stratum }^{a}\end{array}$} & \multicolumn{6}{|c|}{ Livestock species } & \multirow[t]{2}{*}{ Total } \\
\hline & & Sheep & Goat & Cattle & Yak & Horse & Camel & \\
\hline \multirow{3}{*}{$\begin{array}{l}\text { Kazakh } \\
(n=7)\end{array}$} & $\operatorname{Lh}(n=0)$ & & & & & & & \\
\hline & $\operatorname{Mh}(n=3)$ & 235 & 385 & 13 & 0 & 16 & 1 & 650 \\
\hline & $\operatorname{Sh}(n=4)$ & 150 & 370 & 7 & 0 & 7 & 1 & 535 \\
\hline \multirow{3}{*}{$\begin{array}{l}\text { Torguud } \\
(n=12)\end{array}$} & $\operatorname{Lh}(n=6)$ & 300 & 430 & 70 & 0 & 111 & 0 & 911 \\
\hline & $\operatorname{Mh}(n=5)$ & 183 & 227 & 43 & 0 & 42 & 0 & 495 \\
\hline & $\operatorname{Sh}(n=1)$ & 10 & 10 & 20 & 0 & 1 & 0 & 41 \\
\hline \multirow{3}{*}{$\begin{array}{l}\text { Uriankhai } \\
(n=24)\end{array}$} & $\operatorname{Lh}(n=0)$ & & & & & & & \\
\hline & $\operatorname{Mh}(n=4)$ & 140 & 510 & 5 & 41 & 15 & 0 & 711 \\
\hline & $\operatorname{Sh}(n=20)$ & 201 & 1810 & 35 & 80 & 87 & 4 & 2217 \\
\hline
\end{tabular}

Kruskal-Wallis test: across species, no significant differences in dzud losses $(p>0.05)$ between ethnic groups and wealth strata

aHouseholds owning large herds (Lhs), medium-size herds (Mhs) and small herds (Shs)

many animals (23 to 300 head per $\mathrm{HH}$ ). Twenty-one herders stated that the $d z u d$ damage had rendered them depressed, and one even mentioned the need for mental support afterwards. On the other hand, 22 herders said that their mental status was not much affected by the losses. Altogether, $63.8 \%$ of the interviewed herders had decided to apply more effective strategies against $d z u d$ losses in the future, whereas $36.2 \%$ did not anticipate changing their management despite the important livestock losses. Some of the latter herders felt that "not much more' action was needed $(n=11)$, implying that they already had protected their livestock well and minimized as much as possible the losses in the 2009/10 $d z u d$. However, six interviewees of the Sh stratum specified that they were by no means able to improve their efforts.

The major disaster-aversion strategies envisaged for the future were intensified hay-making and hay-stocking

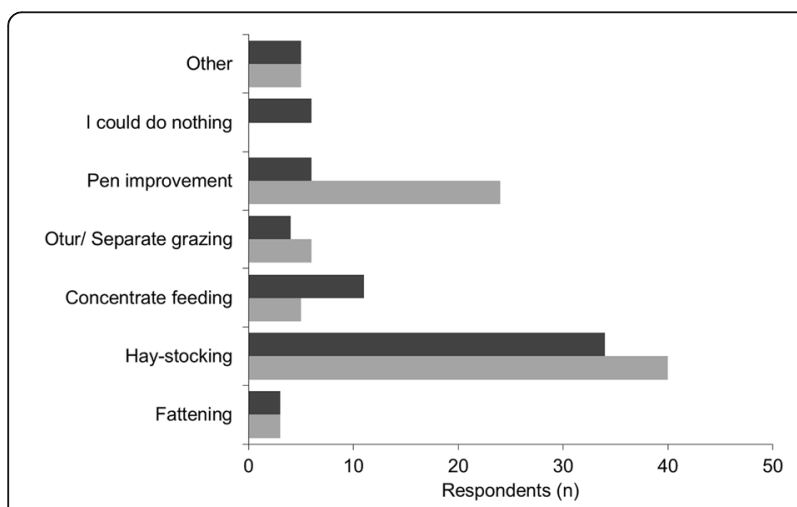

Figure 2 Protective strategies actually implemented against the 2009/10 dzud (dark grey) and measures perceived necessary (light grey) by 50 interviewed herder households in the Mongolian Altai. Multiple answers were possible $(n=24)$ and improvement of the animals' winter pen and surrounding fence $(n=19)$. Additionally, respondents stated that:

" Herders should overcome $d z u d$ by their own efforts (TN03).

" I improve the effectiveness of daily grazing (TN22).

* I care for the management of spring pasture (HS04).

" I care more about health management of livestock (DT01, DT02).

* I start hay-stocking earlier than usual (DT09).

* I stock firewood (HSO1).

Several herders also stated that 'pasture condition improves after $d z u d$ ' $(n=12)$, thereby pointing to the notion that, as a result of decreased livestock numbers and high snow cover (later on turning into melt water), the biomass yield of herbaceous plants on pastureland will typically be high in the year following a snowy (white) $d z u d$. Such high forage availability fosters the nutrition of the remaining livestock and their offspring. Herders also believed that the post- $d z u d$ environment prevents livestock diseases (TN03) and that there will be 'no problem' after $d z u d(n=14)$. There were, however, also some negative notions such as 'mites will increase after $d z u d$ so that health management of livestock becomes difficult' (TN08). A major concern was the lack of manpower for hay-making, which has to start much earlier and/or be of longer duration in a post- $d z u d$ year $(n=9)$ if herders want to benefit from the improved soil moisture conditions in spring and the resulting higher biomass yield on hay fields.

Concerning environmental conditions that would reduce the risk of $d z u d$ damage, the answers $(n=44)$ were limited to two aspects: 'warm weather' and/or 'not so much snowfall' (Figure 3). Herders were not only afraid of snowfall per se but also feared that the snow would

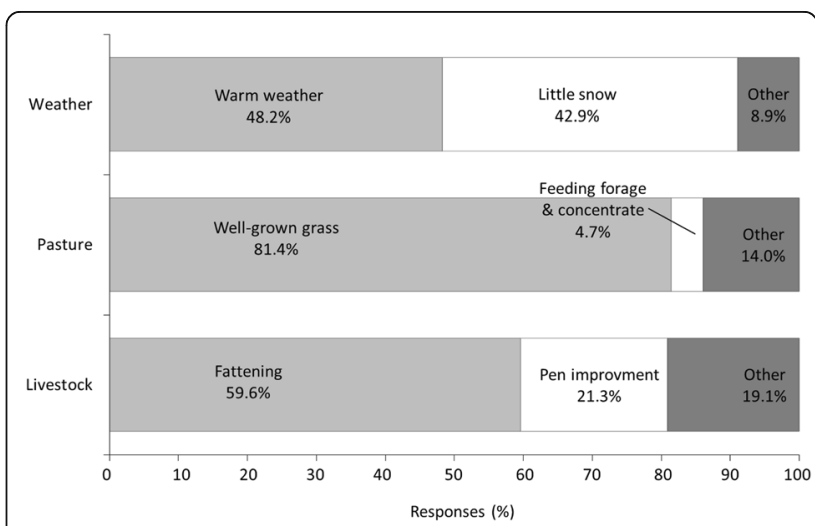

Figure 3 Weather and pasture conditions as well as livestock management options potentially reducing the severity of a dzud as perceived by 50 interviewed herders in the Mongolian Altai 
not melt and would therefore cover the grassland during the whole winter, which makes daily grazing of livestock very difficult. Another concern was related to social aspects, because 'there were conflicts over limited hay and grass, especially between herders of Bulgan (Bulgan [county] soum of Khovd Province) and New Bulgan county (Bulgan [county] soum of Bayan Ölgii Province)' (TN11).

\section{Environmental signs announcing dzud}

Precognition of natural disaster is well established among nomadic herders in Mongolia (Middleton et al. 2015). However, some interviewees perceived this as a form of vanishing local tradition: 'Old people recognized $d z u d$ from specific environmental signs, but we (current people) cannot interpret these' (DT03). Still, the interviewed herders stated to recognize initial signs of $d z u d$ from the weather $(n=21)$ and the grass condition $(n=$ $11)$. These signs can be summarized as cold temperatures and scarce grass in summer and heavy snowfall in winter (Figure 4). If the snow cover is thick, especially sheep and goats cannot easily graze the winter pastures. Three herders were also concerned about the quality and quantity of the initial snowfall in October - if the first snow falls earlier or stronger than normally, the winter may be prolonged or characterized by severe weather conditions. This sign is especially important if appearing between 10 and 15 October (TN11). The snow cover will render the air cold (DT12), which makes the herders realize the risk of $d z u d$. When snowfall continues for two to three days in the beginning of winter, animals weaken and loose body condition (AH05, TN22). In such a case, the herders will check the weather news every day (AH04).

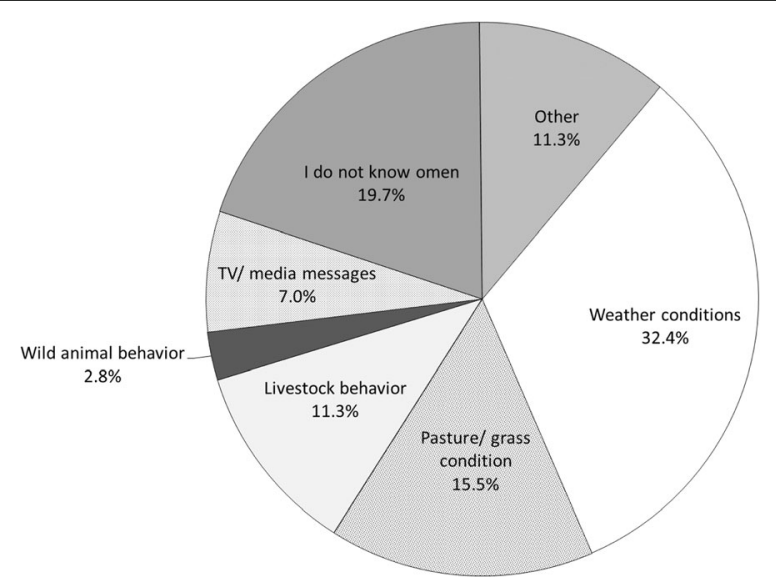

Figure 4 Sources of information and omen indicating dzud to 50 interviewed herders in the Mongolian Altai. Multiple answers were possible
Further environmental signs indicating $d z u d$ are:

* If wormwood (Artemisia absinthium L.) increases and grows tall in the pasture, the winter brings a lot of heavy snowfall (TN20, TN21, DT14).

* If grass is scarce in June (TN21).

* If grass is scarce in summer, drought disaster may occur in winter (TN22).

* If it rains a lot in summer, much snow is expected in winter (HS04, DT13).

* If snow on mount Munkh Khairkhan looks black or dark in summer, $d z u d$ may occur (DT01).

* If tree leaves turn into colour from their bottom, the winter becomes very cold (DT06).

* If downward air current occurs in winter (TN20).

* If the first snowfall is heavy, the winter will provide a cold environment (DT04).

* Old people recognize $d z u d$ from a very thin crescent moon (TN03, TN18).

* If the crescent moon is seen in January, the air becomes very cold (TN18).

* If a strong wind continues from spring onwards (DT14).

* Every 10th year does bring a $d z u d$, such as 1967, 1977, 1987, 1997, 2007/08 (TN02, HS01, DT14).

The behaviour of livestock and wild animals, especially in autumn season, can also indicate a severe winter:

* If sheep and goats give birth in autumn (normally young stock is born in spring) (TN21).

* If livestock start to look for grass from early morning to evening time (TN19, DT06, DT11).

* If livestock seek grass at the foothills, dzud may occur. If they search on the mountain slopes, no $d z u d$ will occur (DT11).

* If livestock have thick hair on their belly (TN18, TN19, HS04).

* If birds and marmots (Gray or Altai marmot, Marmota baibacina) make special protection against snow at their nest/burrow (TN02).

* If marmots disappear earlier from the land in autumn, the spring season will come earlier. Birds act the same (TN01).

* If black marmots (Tarbagan marmot, Marmota sibirica) put stones in front of the burrow as snow barrier, $d z u d$ will occur; gray marmots put their faeces instead of stones (TN02).

* If black marmots start hibernation during September 10-15, then dzud may happen. They normally start hibernation around September 20 (DT06).

* If migratory birds fly away at very high altitude (normally they fly away in the low sky) (DT06). 
Several herders $(n=13)$ stated that it is difficult to foresee $d z u d$ ', or 'I do not know the specific signs of $d z u d$ '. Nowadays, almost all herders have a TV in their ger, and weather forecasts are very important to predict the coming winter (AH04, AH08, TN01, TN08, TN09). One person pointed out that close communication with neighbours and community members in autumn results in a better recognition of $d z u d$ and in consequence earlier preparation and prevention of disastrous damage (HS01). Summing up these discussions, 36.3\% of the herders seemed to recognize the probability of a $d z u d$ in October and November. Only five herders stated that they can predict a $d z u d$ already in summer, whereas four herders admitted to recognizing $d z u d$ only in spring time (February, March), if severe winter weather still prevails.

\section{Perceived responsibilities of local government}

Overall, the interviewed households were quite critical with respect to the governmental services received during the 2009/10 dzud. More than half of the herders $(n=27)$ suggested that the primary measure before and during $d z u d$ should be 'to supply hay stock' (Figure 5). For them, this measure seemed to be more easily achievable than a systematic insurance of livestock against losses or long-term improvements of pastoral resources that the administration could initiate. Together with hay-stocking, 'storage and distribution of concentrate feed (or forage)' was heavily demanded $(n=8)$ and expected from the government to prevent $d z u d$ damage $(n=7)$. High prices of concentrate feed and forage were strongly criticized, and one interviewee requested price reduction in the event of $d z u d$. Official help for pen improvement was also mentioned $(n=5)$. Key problems that originate in the nature of the herding livelihood and which require government action were identified as lack of manpower

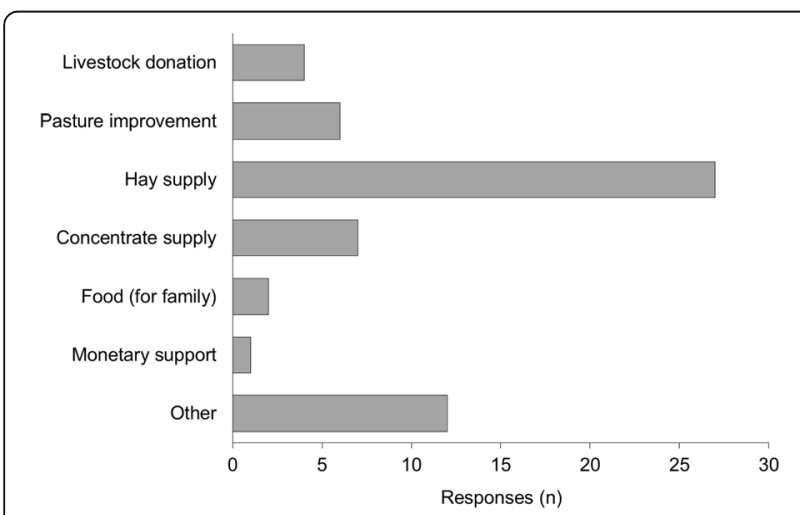

Figure 5 Expectations of 50 interviewed herders towards actions of the local government in the aftermath of dzud in the Mongolian Altai. Multiple answers were possible for hay-making and forage-stocking and the need for material supply for pen improvement $(n=2)$. Other government measures expected during a $d z u d$ were:

* Purchase of skinny livestock (HS04)

* Warm clothing and food for humans (TN19)

* Mental support of herders through consultation (TN03)

* Social insurance or subsidies for herders (TN15)

* Job opportunities in the public or administrative sector (TN22)

Herders also complained about the very poor condition of the local road that was heavily damaged by snow and ice during the 2009/10 dzud (TN11), noting that 'this place is far away from Ulaanbaatar and the administrative centre. We therefore have difficulties in acquiring rescue goods (e.g. concentrate feed, hay, veterinary medicine and care) and services' (DT04, DT08). Further comments collected from the respondents are listed in Table 5; they indicate that herders perceived a lack of effort by the local administration: 'The administration has never given us hay and concentrate although they always claim to provide support for herders' (TN02, DT05, DT06, HS03). Several herders alluded to personal use and prior distribution of rescue goods to kin and close friends of administrative staff: 'If the government provides subsidy to the counties, the county (administration) will use everything. So, a simple monetary compensation should be avoided' (HS04). Yet, two herders stated that 'we need to be ready for our hay stock, and do the necessary preparations by ourselves/our family - this is no governmental issue' (TN02, TN11). This comment might either be understood as self-criticism or as resignation towards the administration. Other statements were: 'We should not increase livestock numbers recklessly. It needs a lot of grass and pastureland in the herding territory' (DT12). 'A large number of livestock was grazed at the onset of the 2009/10 dzud despite rather poor grass conditions on the pastures' (TN21). Therefore, 'sustainable pastureland improvement needs to be more seriously activated, and we should not increase too much our livestock' (DT12, TN21).

\section{Discussion}

The central aim of this study was to evaluate whether in very remote rural areas of Mongolia where infrastructure and government support are deficient, livestock herders use traditional and local ecological knowledge to predict and cope with winter disasters. The relevance of this topic was also underlined in the study by Middleton et al. (2015). To put into perspective the importance of local ecological knowledge for herders in the two Bulgan counties of Bayan-Ölgii and Khovd provinces, we 
Table 5 Notable comments of individual local elders concerning lessons learned from the 2009/10 dzud and possible measures that in the future could reduce disastrous dzud effects in the Mongolian Altai

\begin{tabular}{|c|c|}
\hline $\begin{array}{l}\text { TN02 } \\
\text { (74 years old; Uriankhai) }\end{array}$ & $\begin{array}{l}\text { 'Both livestock and herders need to be more cautious and active to cope with disaster. } \\
\text { If dzud is coming, their weakness can be recognized soon. However, a herder's work } \\
\text { load is hard every day during summer. This means lack of manpower for preparation } \\
\text { against severe winter. The county has never cooperated with herders even though they } \\
\text { always disseminate top-down supports and pretend to help local residents. They also } \\
\text { need to educate young herders for the future, how to graze or to protect livestock. } \\
\text { Share of knowledge should be indeed our Mongolian tradition...' } \\
\text { [interview on } 9 \text { August 2013]. }\end{array}$ \\
\hline $\begin{array}{l}\text { TN1 } 1 \\
\text { (63 years old; Kazakh) }\end{array}$ & $\begin{array}{l}\text { 'For more than } 60 \text { years of life in Bulgan, we need to prepare three things; (1) Protection } \\
\text { against nature, (2) own mental strength, and (3) care for livestock. The old generations } \\
\text { understood well how to deal with changing nature and dzud disaster, but we do not } \\
\text { well know any more. Our families had over } 800 \text { livestock, but only } 25 \text { goats and } 13 \\
\text { sheep are left after the last dzud disaster (2009/10). Heavy snowfall makes the road } \\
\text { condition very bad. As a result, relief goods do not reach the detached places. It also } \\
\text { means a collapse of the life line for us' [interview on } 10 \text { August 2013]. }\end{array}$ \\
\hline $\begin{array}{l}\text { TN20 } \\
\text { (72 years old; Uriankhai) }\end{array}$ & $\begin{array}{l}\text { 'The road condition became very bad during the last dzud (2009/10). Many relief goods } \\
\text { were only delivered to the Bulgan county center. The chief and the administration staff } \\
\text { would not distribute the goods to remote places. We did not get anything at that time!' } \\
\text { [interview on } 11 \text { August 2013]. }\end{array}$ \\
\hline $\begin{array}{l}\text { HS03 } \\
\text { (60 years old; Uriankhai) }\end{array}$ & $\begin{array}{l}\text { The government and county administration announced to prepare hay and clothes for } \\
\text { herders. But we did not get anything at that time! The chief and administration staff } \\
\text { would not distribute the goods to local places' [interview on } 13 \text { August 2013]. }\end{array}$ \\
\hline $\begin{array}{l}\text { DT14 } \\
\text { (58 years old; Uriankhai) }\end{array}$ & $\begin{array}{l}\text { I bought concentrate and hay every week. There were only } 100 \text { packages in the county } \\
\text { center during the last dzud (2009/10), so that it was difficult to obtain. I only got two packages } \\
\text { from the administration. The road condition was deteriorated with snow, so rescue } \\
\text { goods could not reach from Ulaanbaatar. I spent a total of 4,300,000 MNT for hay, } \\
\text { concentrate, and gasoline for transportation. For this purchase, I had to sell all goat } \\
\text { skins ( } 8,000 \text { MNT per piece at that time)...' [interview on } 15 \text { August 2013]. }\end{array}$ \\
\hline
\end{tabular}

explored the livestock losses experienced during the $2009 / 10$ dzud as well as the cumulated livestock losses during the years 2005 to 2010 and compared these to the post- $d z u d$ (2013) livestock possession of the interviewees. We could unfortunately not collect reliable data for the pre- $d z u d$ livestock possession of individual herders, but we might of course have applied the percentage loss of cattle, camels, goats, sheep and yak in Bulgan (National Statistical Office of Mongolia 2014) to each household, so as to reconstruct the 2009 herd sizes. Yet with this approach, we would have postulated that across all herds, the percent losses were the same, which certainly is not true; therefore, we abstained from this exercise.

Overall, low transmission and active application of local ecological knowledge seemed to prevail in the studied households, even though all interviewees acknowledged the significance of such knowledge for predicting $d z u d$, preparing for the disaster and coping with it. However, this knowledge is not much employed in practical terms, neither through action nor cognitive reflection (such as predicting $d z u d$ ). Most interviewees pointed to signs of $d z u d$ that appear earliest in September. This makes it difficult for herders to engage in precautious actions early enough in the vegetation growth cycle. If not already executed as a routine activity, protective measures such as hay-making are constrained by the availability of family labour and are only taking place after families and herds have moved from summer to autumn pastures (Jordan et al. 2016, 2018).

As Berkes (1999) and Baival and Fernandez-Gimenez (2012) reasoned, there is an obvious parallel between resource management strategies based on local ecological knowledge and 'modern' adaptive resources management. According to Berkes (1999), periodic crises evolving around resources use are not disproving the validity of traditional ecological knowledge but might rather lead to its revitalization. In Mongolia and neighbouring regions, $d z u d$ historically limited overpopulation of pastoral landscapes with livestock and even humans (FernandezGimenez 2000), thereby drastically reducing grazing pressure on the natural grassland for several years. This clearly underlines the element of 'nature' and of 'adaptive cycles' (Holling 2001) in this social-ecological system (Ostrom 2007). The adaptation of complex systems to changing conditions takes place through subsequent stages of reorganization, growth, conservation and release or collapse (Holling 2001). The latter, in the present case, were the livestock losses in the 2009/10 dzud, which are presently followed by reorganization, that is, the abandonment of livestock-keeping especially by those Kazakh (Sh) families who lost all their livestock (personal communication with the leader of the Kazakh community in Bulgan county, August 2013). The same was also observed by Sternberg (2010) as a country-wide phenomenon across 
Mongolia and is likewise reported from drought-affected pastoral groups in Western Africa (Starr 1987) and Eastern Africa (Oesterle 2008). Given the economic disparity between the Torguud, of whom $50 \%$ were classified as Lh herders, and the Kazakh and Uriankhai, who mostly belonged to the Sh stratum, vulnerability to $d z u d$ also has an ethnic and an economic dimension, as for example shown by Chen et al. (2013) for the Yangtze River Delta Region. Even though in the Bulgan region all ethnic groups and wealth strata, respectively, kept a high number of goats, Sh and Mh Kazakh households with their goatdominated herds seem to be particularly vulnerable to winter disaster: the respondents and our data indicated that $d z u d$ mortality is very high for this species.

Herd recovery rates after the 2009/10 dzud varied strongly across Mongolia (Middleton et al. 2015). According to official statistics (National Statistical Office of Mongolia 2014), overall livestock losses in the 2009/10 $d z u d$ were 13 and $28 \%$ of the 2009 animal population in the Bayan-Ölgii and Khovd provinces, respectively. In Bulgan soum of Bayan-Ölgii and in Bulgan soum of Khovd, these losses amounted to 54 and 51\%. Whereas by 2013 the post-dzud livestock numbers had substantially increased in Bulgan soum of Bayan-Ölgii (1.54 times the 2010 headcount), in Bulgan soum of Khovd, an increase of only $28 \%$ was recorded (National Statistical Office of Mongolia 2014). Thus, in 2013, herders in the two soums on average kept only $71 \%$ (Bulgan soum of Bayan-Ölgii) and 63\% (Bulgan soum of Khovd) of their 2009 animal numbers, rendering them very susceptible to new disaster in the near future. An analysis of 2010 livestock data also indicated that in the Gobi Desert, which is relatively close to our study region, a high proportion of pastoral herds were smaller than the minimum viable size (Addison and Brown 2014). Similarly, in the north of Bayan-Ölgii province, $80 \%$ of herder households possess less than 200 head of livestock (Soma 2014).

The decrease in livestock numbers in the 2009/10 $d z u d$ and the incomplete recovery in the two studied soums until 2013 led to a substantial increase of available pastureland for the remaining livestock population. The regional utilization patterns of pastureland are greatly influenced by the management strategies of Lh households who possess $55.5 \%$ of the total regional livestock and dominate on qualitatively and quantitatively better pastureland (Altmann et al. 2016). On the other hand, especially $\mathrm{Mh}$ and Sh herders tend to live together in khot ail summer pasture settlements for cooperative grazing purposes and work-sharing. For the Tsunhal Nur (TN) pasture, Altmann et al. (2016) determined an average stocking density of 2.5 sheep units (SUs, herbivore animal of $45-\mathrm{kg}$ live weight) per hectare in summer 2014, whereas the median was only 1.6 SU/ha. Whereas Kazakh HHs kept on average 3.5 SU/ha on the summer grazing areas attributed to their use, the respective stocking density was $1.2 \mathrm{SU} /$ ha for Uriankhai and 2.7 SU/ha for Torguud (Altmann et al. 2016). From remotesensing-based biomass estimates in June 2014, these authors calculated an average offer of dry herbaceous forage mass of 424 to $1053 \mathrm{~kg} / \mathrm{ha}$ per herd, with a median of 611 (Altmann et al. 2016). Together with a reduced rotation of herds between grazing areas within a seasonal pasture, and shortened distances of the daily grazing orbits (Jordan et al. 2016), pasture conditions may thus deteriorate easily (Tsui 2012) in specific areas.

Livestock losses in the 2009/10 dzud were exacerbated by a general decline in the government's pastoral support services since the transition to a market economy (Fernandez-Gimenez 1999; Sternberg 2010; Addison and Brown 2014). In view of this, and especially based on the herders' analysis of the effectiveness of official versus private measures, it becomes clear that local strategies of preventive herd and pastureland management are more important than governmental interventions in the study region. Addison and Brown (2014) collected a cascading series of livestock-loss-preventing strategies that are employed by herders in the Gobi Desert, such as haymaking, selling off lean animals in autumn, deciding against mating and purchasing supplementary feed for specific animals. By modelling the economic return to these strategies for a good, normal and harsh winter, they demonstrated the relevance of markets as nontenured institutions for coping with adverse environmental conditions. However, few markets for trading animals, livestock products and inputs such as feed exist in the aimags studied by Addison and Brown (2014) and are quasi-absent in the westernmost region of Mongolia where our study took place. Herders in this region therefore have to rely on local non-market-oriented coping strategies, most frequently portrayed as winter pen preparation and hay-making. However, a few of our respondents mentioned early sale or slaughter of skinny animals and strategic mating, similar to such knowledge of their peers in the Gobi Desert (Addison and Brown 2014) and beyond (Fratkin and Mearns 2003). The bytrend different proportions of livestock lost in different wealth strata indicate that local herders need a basic socio-economic stability, granted primarily by herd size, in order to maintain a minimum of food and livelihood security during crisis (Greatrex et al. 2015). Economic stability of livestock-keeping households relies in particular on the survival of (re-)productive animals and replacement breeding females (Tsevegmed 2016). Therefore, as the first local strategic axis, appropriate summer grazing and mating practices are laying the basis for such survival, and the practice of otor improves the body condition of selected animals that may be sold after summer to purchase feed stocks (Addison and Brown 
2014). A high herd mobility that involves frequent rotation of grazing areas in summer promotes well-nourished animals and prevents overgrazing in the semi-arid and arid landscapes of Inner Asia (Sneath 1998; Tsui 2012). For the Mongolian provinces of Arkhangai and Bayankhongor, Fernandez-Gimenez et al. (2015) reported that otor and other traditional resources management practices significantly increased after the 2009/10 dzud in formally organized community groups as compared to individual households. In our study region, where households operate individually or at best on a khot ail basis, the practice of otor has vanished due to a lack of manpower for herding, which in summer competes with milking and milk-processing, vaccinating livestock, shearing sheep and felting wool (Tsevegmed 2016). By controlling livestock-mating, herders determine the timing of livestock parturitions (AH04, AH06). The best mating period for cattle and yak is in early summer and for small ruminants in autumn; in this way, all animals will give birth during the following March (TN20), when the harsh winter months are normally over. If parturitions occur substantially later, newborn animals will reach insufficient physical maturity by the start of the next winter (AH08). Similarly, if the herd comprises many relatively old (and weak) animals, this may also lead to increased animal losses (AH05). These insights of the local herders concerning the relevance of strategic animal mating and selling strategies are fully supported by the results of interviews and economic modelling targeting the Gobi Desert (Addison and Brown 2014).

The second local strategic axis concentrates on herd survival in very harsh winters. To this end, building up a hay stock and fortifying the winter pen and fence in autumn are key measures. Since faeces of bovine species are required for fire-making and insulation of the pen floor, low cattle numbers threaten a family's recourse to these strategies. Similarly, and even more importantly, a lack of (adult) manpower severely challenges the ability to preserve enough winter fodder in many herder families. Even though the first and second axes of local strategies are synergistic, most of the interviewed herders only referred to second-axis strategies. Regional and national governmental and non-governmental organizations cooperating with herders in the Khovd and Bayan-Ölgii provinces should therefore aim to revitalize the practice of first-axis strategies as well.

\section{Conclusions}

Our data indicate that in remote rural counties of the Mongolian Altai mountains, livestock losses in the 2009/10 dzud were very high and in particular affected herders with smaller and/or goat-dominated herds, who often were of Kazakh and Uriankhai ethnicity. Whereas Uriankhai households and the wealthier Torguud herders pursued a quick re-stocking of herds, small-scale Kazakh herders abandoned livestock-keeping. For a majority of herders, local ecological knowledge of predicting harsh winters and taking precautions against such disaster gained importance only after the 2009/10 dzud. Therefore, priority was given to hay-making and winter pen preparation, whereas improvement of livestock productivity through segregated grazing (otor) of selected animals, frequent pastureland rotation of the main herd, controlled mating and early sale of fattened as well as skinny livestock were sometimes mentioned but hardly practiced. Since animals that enter the winter season in healthy and well-fed condition are more resistant against disaster than lean animals, national and international organizations wishing to support livestock keepers in this and similar regions should highlight the relevance of these local approaches. However, labour investments in refined herding strategies, hay-making and winter pen preparation can be substantial and surpass the capacities of individual households. Therefore, community-based activities are highly advisable.

\section{Endnotes}

${ }^{1}$ The reference Tsevel (1966) was suggested to the authors by one of the anonymous reviewers.

${ }^{2}$ These abbreviations indicate individual answers, whereby the letters stand for the summer pasture location and the number for the household.

\section{Abbreviations \\ HH: Household; LEK: Local ecological knowledge; SU: Sheep unit; \\ TEK: Traditional ecological knowledge; TLP: Total livestock possession}

\section{Acknowledgements}

This research has been carried out with financial support from the WATERCOPE Project, financed by the International Fund for Agricultural Development (IFAD, Rome, Italy; Grant No. I-R-1284). We are grateful to all cooperating households for their hospitality and time spent in answering our questions and to two anonymous reviewers as well as Prof. Dr. Andreas Buerkert, Universität Kassel, for very valuable advice on earlier versions of this manuscript.

\section{Funding}

This study was part of the WATERCOPE Project funded by the International Fund for Agricultural Development (IFAD) Rome, Italy (Grant No. I-R-1284).

\section{Availability of data and materials}

Detailed data and information that underlie this manuscript will be made available to interested readers upon request by email to the corresponding author.

\section{Authors' contributions}

TS conceived the study, carried out the field research, analysed the data and drafted the manuscript. ES advised on the fieldwork, participated in the data analysis and composed the final version of the manuscript, which both authors read and approved.

\section{Authors' information}

TS is assistant professor at the Waseda Institute for Advanced Studies in Tokyo, Japan. The manuscript presents results of his two-year research project on Traditional and present livestock husbandry practices in the Mongolian Altai Mountains'. ES is professor and head of the section of Animal Husbandry in the Tropics and Subtropics at the University of Kassel and the University of Göttingen, Germany. 


\section{Ethics approval and consent to participate}

All households and household members, who participated in this interviewbased study, did so voluntarily after having been informed about the aims and scope of the study and with the insurance that their identity would not be revealed.

\section{Consent for publication}

Not applicable in the present context.

\section{Competing interests}

The authors declare that they have no competing interests.

\section{Publisher's Note}

Springer Nature remains neutral with regard to jurisdictional claims in published maps and institutional affiliations.

\section{Author details \\ ${ }^{1}$ Section Animal Husbandry in the Tropics and Subtropics, University of Kassel and Georg-August-Universität Göttingen, Steinstrasse 19, 37213 Witzenhausen, Germany. ${ }^{2}$ Current address: Waseda Institute for Advanced Studies, Waseda University, 1 Chome-104 Totsukamachi, Shinjuku, Tokyo 169-8050, Japan.}

\section{Received: 30 May 2017 Accepted: 28 November 2017}

\section{Published online: 29 January 2018}

\section{References}

Addison, J., and C. Brown. 2014. A multi-scaled analysis of the effect of climate, commodity prices and risk on the livelihoods of Mongolian pastoralists. Journal of Arid Environments 109: 54-64. doi:https://doi.org/10.1016/j.jaridenv. 2014.05.010.

Altmann, B., G. Jordan, and E. Schlecht. 2016. A community-based approach to identifying grazing pressure and land use management structures among herders in the Altay Mountains, Mongolia, Proceedings of the X International Rangeland Congress, July 16-22, 2016, 785-787. Saskatoon.

Baival, B., and M.E. Fernandez-Gimenez. 2012. Meaningful learning for resilience building among Mongolian pastoralists. Nomadic Peoples 16 (2): 53-77. doi:https://doi.org/10.3167/np.2012.160205.

Begzsuren, S., J.E. Ellis, D.S. Ojima, M.B. Coughenour, and T. Chuluun. 2004. Livestock responses to droughts and severe winter weather in the Gobi Three Beauty National Park, Mongolia. Journal of Arid Environments 59 (4): 785-796. doi:https://doi.org/10.1016/j.jaridenv.2004.02.001.

Berkes, F. 1999. Sacred ecology: Traditional ecological knowledge and resource management. Philadelphia: Taylor and Francis.

Bold, B.-O. 1996. Socio-economic segmentation - "Khot-Ail" in nomadic livestock keeping of Mongolia. Nomadic Peoples 39: 69-86.

Chapman, P.M. 2007. Traditional ecological knowledge (TEK) and scientific weight of evidence determinations. Marine Pollution Bulletin 54: 1839-1840. doi:https://doi.org/10.1016/j.marpolbul.2007.10.033.

Chen, W., S.L. Cutter, C.T. Emrich, and P. Shi. 2013. Measuring social vulnerability to natural hazards in the Yangtze River Delta region, China. International Journal of Disaster Risk Science 4: 169-181.

Fernandez-Gimenez, M.E. 1999. Sustaining the steppes: A geographical history of pastoral land use in Mongolia. The Geographical Review 89 (3): 315-342. doi:https://doi.org/10.2307/216154

Fernandez-Gimenez, M.E. 2000. The role of Mongolian nomadic pastoralists' ecological knowledge in rangeland management. Ecological Applications 10: 1318-1326. doi:https://doi.org/10.2307/2641287.

Fernandez-Gimenez, M.E., B. Batkhishig, B. Batbuyan, and T. Ulambayar. 2015. Lessons from the dzud: Community-based rangeland management increases the adaptive capacity of Mongolian herders to winter disasters. World Development 68: 48-65. doi:https://doi.org/10.1016/j.worlddev.2014.11.015.

Fernandez-Gimenez, M.E., B. Batkhishiga, and B. Batbuyan. 2012. Cross-boundary and cross-level dynamics increase vulnerability to severe winter disasters (dzud) in Mongolia. Global Environmental Change 22 (4): 836-851. doi:https:// doi.org/10.1016/j.gloenvcha.2012.07.001.

Fernandez-Gimenez, M.E., N.H. Venable, J. Angerer, S. Fassnacht, and K. Jamyansharav. 2016. Ecological-cultural feedbacks in Mongolian socialecological systems, Proceedings of the X International Rangeland Congress, July 16-22, 2016, 515-517. Saskatoon.
Fratkin, E., and R. Mearns. 2003. Sustainability and pastoral livelihoods: Lessons from East African Maasai and Mongolia. Human Organization 62: 112-122.

Greatrex, H., J.W. Hansen, S. Garvin, R. Diro, S. Blakeley, M. Le Guen, K.N. Rao, and D.E. Osgood. 2015. Scaling up index insurance for smallholder farmers: Recent evidence and insights. CCAFS report no. 14. Copenhagen: CGIAR Research Program on Climate Change, Agriculture and Food Security (CCAFS) Available at: https://ccafs.cgiar.org/publications/scaling-index-insurancesmallholder-farmers-recent-evidence-and-insights\#.WkPzu3kiHIU.

Holling, C.S. 2001. Understanding the complexity of economic, ecological and social systems. Ecosystems 4: 390-405. doi:https://doi.org/10.1007/s10021-0010101-5.

Indrawan, M., M. Yabe, H. Nomura, and R. Harrison. 2014. Deconstructing satoyama - the socio-ecological landscape in Japan. Ecological Engineering 64: 77-84. doi:https://doi.org/10.1016/j.ecoleng.2013.12.038.

Jordan, G., S. Goenster, T. Munkhnasan, A. Shabier, A. Buerkert, and E. Schlecht. 2016. Spatio-temporal patterns of herbage availability and livestock movements: A cross-border analysis in the Chinese-Mongolian Altay. Pastoralism: Research, Policy and Practice 6: 12. doi:https://doi.org/10.1186/ s13570-016-0060-2.

Jordan, G., S. Goenster-Jordan, G.-J. Lamparter, B. Ulziisuren, N. Soninkishig, E. Schlecht, and A. Buerkert. 2018. Water use in agro-pastoral livelihood systems within the Bulgan River watershed of the Altay Mountains, Western Mongolia. Agriculture, Ecosystems and Environment 251: 180-193. doi:https:// doi.org/10.1016/j.agee.2017.09.008.

Martin, J.F., E.D. Roy, S.A.W. Diemont, and B.G. Ferguson. 2010. Traditional ecological knowledge (TEK): Ideas, inspiration, and designs for ecological engineering. Ecological Engineering 36: 839-849. doi:https://doi.org/10.1016/j.ecoleng.2010.04. 001.

Mebratu, D. 1998. Sustainability and sustainable development: Historical and conceptual review. Environmental Impact Assessment Review 18 (6): 493-520. doi:https://doi.org/10.1016/S0195-9255(98)00019-5.

Menzies, C.R., ed. 2006. Traditional ecological knowledge and natural resource management. Lincoln: University of Nebraska Press.

Middleton, N., H. Rueff, T. Sternberg, B. Batbuyan, and D. Thomas. 2015. Explaining spatial variations in climate hazard impacts in western Mongolia. Landscape Ecology 30 (1): 91-107. doi:https://doi.org/10.1007/s10980-014-0091-2.

Mroz, L. 2015. The trans-Altai Torgut and Bulgan after forty years. Ethnologia Polona 36: 31-51.

Murphy, D.J. 2014. Booms and busts: Asset dynamics, disaster, and the politics of wealth in rural Mongolia. Economic Anthropology 1: 104-123.

National Statistical Office of Mongolia. 2014. Mongolian statistical yearbook. Ulaanbaatar.

Oesterle, M. 2008. From cattle to goats: The transformation of east Pokot pastoralism in Kenya. Nomadic Peoples 12: 81-91.

Ostrom, E. 2007. A diagnostic approach for going beyond panaceas. Proceedings of the National Academy of Sciences of the United States of America 104 (39): 15181-15187.

Saizen, I., A. Maekawa, and N. Yamamura. 2010. Spatial analysis of time-series changes in livestock distribution by detection of local spatial associations in Mongolia. Applied Geography 30 (4): 639-649. doi:https:/doi.org/10.1016/j. apgeog.2010.01.002

Saruul, S. 2011. Mongol costumes. Ulaanbaatar: Academy of National Costumes.

Schafer, A.G., and E.G. Reis. 2008. Artisanal fishing areas and traditional ecological knowledge: The case study of the artisanal fisheries of the Patos Lagoon estuary (Brazil). Marine Policy 32: 283-292. doi:https://doi.org/10.1016/j.marpol. 2007.06.001.

Sneath, D. 1998. State policy and pasture degradation in Inner Asia. Science 281: 1147-1148. doi:https://doi.org/10.1126/science.281.5380.1147.

Soma, T. 2014. Current situation and issues of recent transhumant animal husbandry in Sagsai County, Bayan Ulgii Prefecture, Western Mongolia. E-Journal GEO 9 (1): 102-119.

Sonak, S.M. 2014. Khazan ecosystems of Goa: Building on indigenous solutions to cope with global environmental change. Dordrecht: Springer.

Starr, M.A. 1987. Risk, environmental variability and drought-induced impoverishment: The pastoral economy of central Niger. Africa 1: 29-50.

Sternberg, T. 2010. Unravelling Mongolia's extreme winter disaster of 2010. Nomadic Peoples 14 (1): 72-86. doi:https://doi.org/10.3167/np.2010.140105.

Teixeira, J.B., A.S. Martins, H.T. Pinheiro, N.A. Secchin, R.L. de Moura, and A.C. Bastos. 2013. Traditional ecological knowledge and the mapping of benthic marine habitats. Journal of Environmental Management 115: 241-250. doi:https://doi.org/10.1016/j.jenvman.2012.11.020. 
Tsevegmed, M. 2016. Herd management and livestock productivity in the Altai region of Western Mongolia, PhD thesis. Kassel: University of Kassel http://nbnresolving.de/urn:nbn:de:hebis:34-2016081750692.

Tsevel, Y. 1966. Concise explanatory dictionary of the Mongolian language. Ulaanbaatar: State Publishing Committee.

Tsui, Y. 2012. Swinging between nomadism and sedentarism: A case study of social and environmental change in the nomadic society of the Altay steppes, Xinjiang. Nomadic Peoples 16 (1): 50-67. doi:https://doi.org/10.3167/np.2012. 160106.

Turvey, S.T., C. Fernández-Secades, J.M. Nuñez-Miño, T. Hart, P. Martinez, J.L. Brocca, and R.P. Young. 2014. Is local ecological knowledge a useful conservation tool for small mammals in a Caribbean multicultural landscape? Biological Conservation 169: 189-197. doi:https:/doi.org/10.1016/..biocon.2013.11.018.

WECD. 1987. Our common future. World Commission on Environment and Development. Oxford: Oxford University Press.

\section{Submit your manuscript to a SpringerOpen ${ }^{\odot}$ journal and benefit from:}

- Convenient online submission

- Rigorous peer review

- Open access: articles freely available online

- High visibility within the field

- Retaining the copyright to your article

Submit your next manuscript at $\gg$ springeropen.com 